\title{
Erratum
}

\section{The PLSI Method of Stabilizing Two-Dimensional Nonsymmetric Half-Plane Recursive Digital Filters}

\author{
N. Gangatharan ${ }^{1}$ and P. S. Reddy ${ }^{2}$ \\ ${ }^{1}$ Department of Electronics and Telecommunication Engineering, Faculty of Engineering, Kigali Institute of Science and Technology \\ (KIST), P.O. Box 3900, Kigali, Rwanda \\ ${ }^{2}$ Department of Electronics and Communication Engineering, SRM University, Kattankulatthur 603203, \\ Kancheepuram Dt, Tamil Nadu, India \\ Correspondence should be addressed to N. Gangatharan, n.gangatharan@kist.ac.rw \\ Received 5 October 2007; Accepted 4 November 2007 \\ Copyright () 2008 N. Gangatharan and P. S. Reddy. This is an open access article distributed under the Creative Commons \\ Attribution License, which permits unrestricted use, distribution, and reproduction in any medium, provided the original work is \\ properly cited.
}

The authors would like to bring to the kind attention of the readers the following corrections to the paper [1].

Equation (23) in page number 917 is as follows:

$$
f=b_{00}^{\prime} \text {. }
$$

It should be noted that in (23) and all equations in the rest of the paper that contain the term $b_{00}^{\prime}$, this term is the constant term of the polynomial $B^{\prime}\left(z_{1}, z_{2}\right)$, which is the stable version of the 2D PLSI polynomial $B\left(z_{1}, z_{2}\right)$. Since we have assumed that $b_{i j}$ 's are the coefficients of the 2D PLSI polynomial, the coefficients of the polynomial $B^{\prime}\left(z_{1}, z_{2}\right)$ are $b_{i j}^{\prime}$ 's.

Equation (46) in page number 920 is as follows:

$$
\begin{aligned}
A\left(z_{1}, z_{2}\right)= & 0.6+0.9 z_{2}+0.3 z_{2}^{2}+0.9 z_{1}+1.5 z_{1} z_{2}+0.9 z_{1} z_{2}^{2} \\
& +0.3 z_{1}^{2}+0.9 z_{1}^{2} z_{2}+0.6 z_{1}^{2} z_{2}^{2}+0.6 z_{1}^{2} z_{2}^{2}+0.5 z_{1} z_{2}^{-1} \\
& +0.8 z_{1}^{2} z_{2}^{-1}+0.7 z_{1} z_{2}^{-2}+z_{1}^{2} z_{2}^{-2} .
\end{aligned}
$$

This equation may be corrected as follows:

$$
\begin{aligned}
A\left(z_{1}, z_{2}\right)= & 0.6+0.9 z_{2}+0.3 z_{2}^{2}+0.9 z_{1}+1.5 z_{1} z_{2} \\
& +0.9 z_{1} z_{2}^{2}+0.3 z_{1}^{2}+0.9 z_{1}^{2} z_{2}+0.6 z_{1}^{2} z_{2}^{2} \\
& +0.5 z_{1} z_{2}^{-1}+0.8 z_{1}^{2} z_{2}^{-1}+0.7 z_{1} z_{2}^{-2}+z_{1}^{2} z_{2}^{-2} .
\end{aligned}
$$

\section{ACKNOWLEDGMENTS}

We would like to thank K. R. Santhi, Department of Computer Engineering and Information Technology, Faculty of
Engineering, Kigali Institute of Science and Technology (KIST), Rwanda, for bringing to our attention one of the above corrections.

\section{REFERENCES}

[1] N. Gangatharan and P. S. Reddy, "The PLSI method of stabilizing two-dimensional nonsymmetric half-plane recursive digital filters," EURASIP Journal on Applied Signal Processing, vol. 2003, no. 9, pp. 914-921, 2003. 